\title{
A Message On the Ruling On Drinking Coffee by Muhammad Bin Muhammad Bin Mustafa Bin Othman Abi Saeed Al-Khademi (1176 Ah): Study and Verification
}

\author{
Dhahir Ali Ahmed Aa'yid \\ General Directorate of Education in Anbar, Ministry of Education, Iraq \\ zahrly422@gmail.com
}

\begin{abstract}
:
The present research contains two sections: First section discusses the author's life which includes: his name, birth, origin, surname, scholars, learners, writings, death, and scientific status. Second section deals with the edited text that involves the scientists' interpretations about the rule of drinking coffee, where some of them interpret it on the basis of its permissible, forbidden, purity, and impurity, then mentioning the author's preponderant opinion.
\end{abstract}

Keywords: $\quad$ Al-Khademi; Coffee; Message; Ruling; Verifying.

Crossref doi https://doi.org/10.51345/.v31i2.356.g175 


$$
\begin{aligned}
& \text { رسالة في حكم شرب القهوة: لمحمد بن حممد بن مصطفى بن عثمان أبي سعيد الخادمي } \\
& \text { (ت } \\
& \text { م.م. ظاهر علي أحمد عايد } \\
& \text { المديرية العامة لتربية الأنبار، وزارة التربية، العراق }
\end{aligned}
$$

\section{ملخص البحثث}

يتناول البحث الحالي جانبين: الأول: يتحدث عن حياة المؤلف وذلك بذكر اسمه، وولادته، ونسبه، ولقبه، و كنيته، وشيوخه، وتلاميذه، ومؤلفاته، ووفاته، ومكانته العلمية. والثاني: فهو النص المحقق والذي تضمن آراء العلماء في الحكم على شرب القهوة، إذ ذهب بعضهم على حلها، وحرمتها، وطهارتها، ونجاستها. ومن ثم بيان القول الراجح للمؤلف. 
المقدمة

الحمد لله ربِّ العالمين والصلاة والسلام على الَمبعُوث رحمة للعالمين سيدنا محمد الأمين وعلى آله وصحبه الغرّ الميامين و التَّبعين لهم بإحسان إلى يوم الدّين. أمَّا بعد: فإنَّ دراسة الفقه الإسلامي من أي جانب، يحقق للمجتمع الذي نعيش فيه، وللعالم بأكمله فوائد

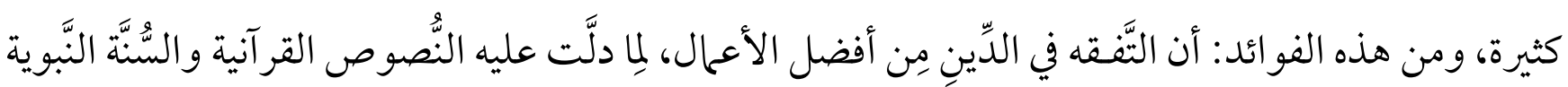

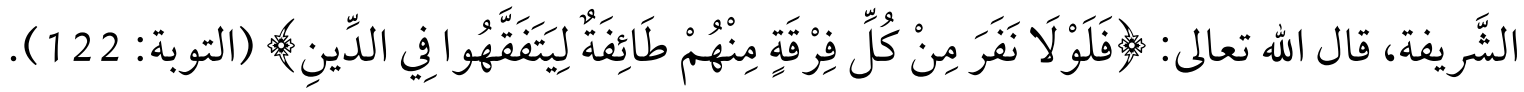
وقوله صلى الله عليه وسلم: (مَن يُرِِ الله به خيرًا يُفقهه في الدّين)(1) كما أنَّ معرفة الأحكام الفقهية المُتعلقة بأفعال النَّاس تُعينُ المسلم على الالتزام بتلك الأحكام، وتضبط حياة الأفراد والجماعات، والمجتمع بمنهج شرعيٍ رشيدٍ، باعتبار أنَّ وظيفة الفقيه، هي أنَّه يقوم بدور استباط صورة تنظيمية كاملة لحياة المجتمع في كل زمان، على ضوء الكتاب والسُّنَّة النَّبوية الشَّريفة.

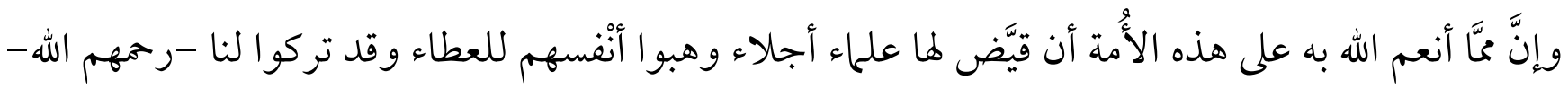
تراثاً عظيحاً، وكنوزاً ثمينة، وثروة علمية عظيمة في شتى أنواع المعارف، فما مِن علم مِن العلوم، ولا فنِّ مِن

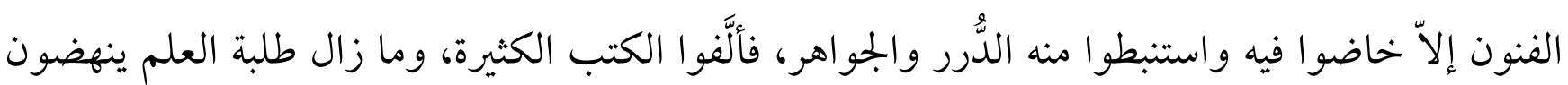
لاستنباط هذه الدّرر من مكامنها وتيسير الحصول عليها. ومن هذه الدرر تحقيق المخطوطات التي فيها منافع لأهل العلم خاصة والناس عامة، وقد حصلت على ثلاث نسخ للمخطوط، الأولى من وزارة الاوقاف المصرية، والثانية من دار الكتب المصرية، والثالثة من المكتبة القادرية، وكان سبب اختياري لتحقيق المخطوط هو: 1 - قيمة الكتاب العلمية والفقهية، حيث يُعتبر من كتب المهمة في المذهب الحنفي. 2- إحياء التُّاث الإسلامي الَّني لم يسنح الفرصة لأصحابه، إن ينشروه ويحققوه حتى يستفيد منه 
غير أنَّ كلَّ عمل يحتاج إلى جهدٍ وتعب، لكي يصل المُريد إلى النَّيجة المَرجوَّة خصوصاً إذا كان هذا العمل

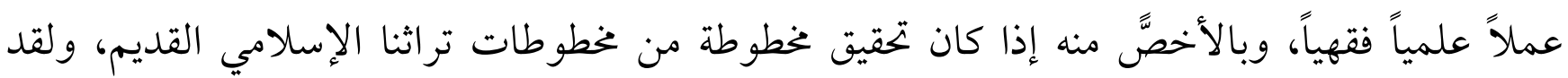

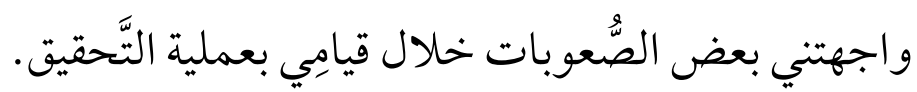

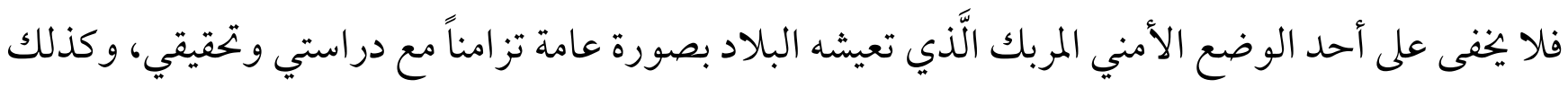
صعوبة الحصول على بعض المصادر التّتي ذكرها المؤلف في كتابه.

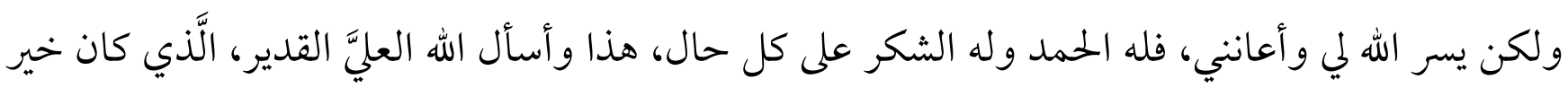

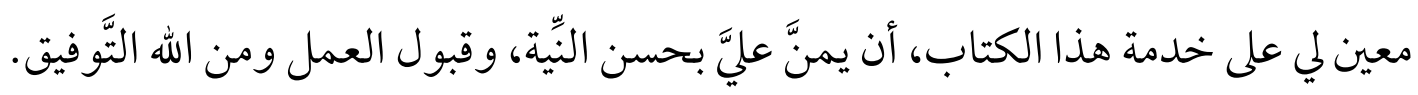

\section{المبحث الأول : بيان حياة المؤلف:}

المطلب الأول: اسمه وولادته ونسبه، ولقببه وكنيته.

أولاً: اسمه:

هو محمد بن محمد بن مصطفى بن عثمان، أبو سعيد، الخنادمي (2).

$$
\text { ثانياً: ولادته ونسبه: }
$$

ولد الخادمي عام 1113هـ - 1701م، أصله من بخارى (3)، ومولده ووفاته في قرية خادم(4)، من توابع

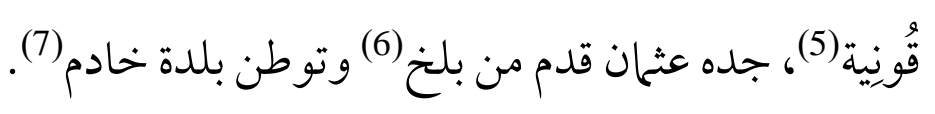

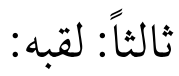

لقب (رمهه الله تعالى) بالقاب متعددة كما وجدتها في كتب التراجم وهي على النحو الاتي:

$$
1
$$

$$
\text { - } 2 \text { - الرومي الحسيني. }
$$




\section{(9) - الحنفي}

لذا فإن لقب الخادمي هو أكثر شهرةً نسبةً إلى قرية (خادم) التي ولد وتوفي فيها(10). رابعًا: كنيته: وكنية الشيخ محمد الخادمي هي: (أبو سعيد)(11).

المطلب الثاني: شيوخه وتلاميذه ورحلاته : أولاً: شيوخه:

تفقَّه على أبيه وجده، وشيخه أحمدي، ولم أعثر له في كتب التراجم على غير ذلك(12). ثانيًا: تاميذه: لم أعثر له على تلاميذ غير واحد وهو، السَيد حسين بن السَيد علي الآيدينى الرومي الحنفِي المغْروف بطات زَاده(13)، درس بِبََلَ الخادمي ثمرفي بَلْدة مغنيسا إلى أن توفي بها سنة 1213 للهجرة، لَه حاشِية على حاشِية السَيد لشرح الْعَضد لمختصر ابْن الَْاجِبَ. وحَاشِيَة على شرح العقائد العضدية(14).

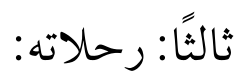

الارتحال في طلب العلم كان ديدن العلماء الأوائل؛ لما له من الأثر في بناء شخصية الأنسان علميًا؛ لذا لم يتخلف الإمام الخادمي عن ركب الأوائل؛ إذارتحل إلى إسطنبول(15) مرتين: الأولى: بعد أن حفظ القرآن الكريم، وقرأ كثيرًا من الكتب في التفسير والحديث والفقه والأصول والكلام والمنطق و البلاغة والتصوف في خادم ارتحل إلى إسطنبول ملتحقًا بدروس أحمدي قضا بادي (16). وفيها انهى الكتب الأساسية لتعلم اللغتين العربية والفارسية حتى نال إجازة فيها| فهو إمام متمكن من اللغة العربية وهذا ما جاء واضحًا في مؤلفاته التي ألفها في اللغة العربية. الثانية: بعد أن عاد إلى خادم و تقلد التدريس في مدرستها حقبة من الزمن .عاد إلى إسطنبول ملتحقًا بدرس الطمأنينة (17). 


\section{المطلب الثالث: مؤلفاته :}

1 - بجمع الحقائق في أصول الفقه. مطبوع- دار الكتب العلمية بيروت- لبنان(د ط)(د ت). - - منافع الدقائق وهو شرح لمجمع الدقائق. مطبوع -تركيا- استانه.

3- حاشية على درر الحكام، في فقه الحنفية. مطبوع في كلية الإمام الأعظم، بتحقيق: علاد منهل سلان الجبوري.

4- البريقة المحمودية في شرح الطريقة المحمدية للبركلي (18) مطبوع- دار الكتب العلمية بيروت- لبنان، تنقيح - أحمد فتحي عبد الرحن.

5- شرح الرسالة الولدية للغزالي وهو مفقود(19). 6- الوصايا. غخطوط غير محقق (20).

7 - حقيقة كلمة التو حيد عند الكاميين والصوفية. غخطوط (21). 8- رسالة في حكم قر اءة آية الكرسي عقب الصلاة. خخطوط(22). 9- خزائن الجواهر. خخطوط (23). 10 - رسالة في تفسير البسملة. مطبوع - في كلية الإمام الأعظم. 11 - حاشية على تفسير سورة الإخلاص. خخطوط محقق في (2016) تحقيق:أ.م هارون بكر اغلو. 12 - حاشية على تفسير سورة النبأ. غخطوط قيد التحقيق في كلية العلوم الاسلامية بغداد/ ثائر جلوي علو ان/ ومحمد حمد الله جمعة.

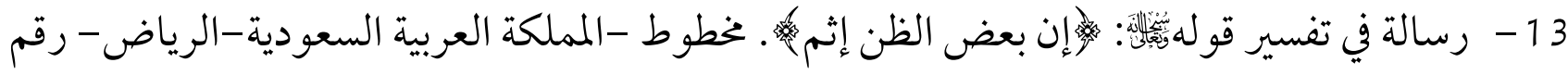
الحفظ: 1588-6

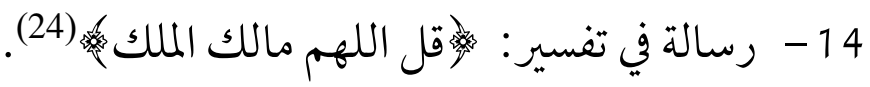

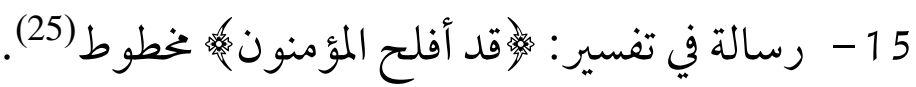
16 - رسالة القهوةُّ والتي انا بصدد تحقيقها. 


\section{المطلب الرابع : مكانته العلهيـة، ووفاته:}

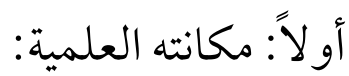

يعتبر الخادمي من علم)ء الحنفية، فقيه، أصولي، محدث، صوفي منطقي، مفسر، درس في خادم كما اشتهر بدرس

ألقاه في آيا صو فيا(26) بإستنبول، في تفسير الفاتحة(27). ثانياً: وفاته:

تذكر كتب التراجم أنَّهُ توفي في قرية خادم في: (1176 هـ)(28).

\section{المبـحث الثاني: منهجي يِّ التحقيق}

\section{أولاً: الجوانب التشكيلية ويشتهل على نقاط:} - - التنقيط والتشكيل ووضع علامات التنصيص. - - مقابلة النسخ بعضها البعض، وإثبات الصو اب من النسخ في المتن. - الإشارة الم الكلمات المأخوذ من النسخ (ب) و(ج) والإشارة إليها في الهامش. - وضع الكلمات أو الجمل الساقطة من النسخة (الأصل) وما أضيفه من النسخ (ب) و(ج) ووضعها

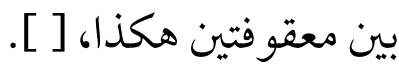
- جعلت النسخة المصرية هي (الأصل)؛ وذلك لقلة السقط، والتحريف، وكونها نسخت قبل النسختين.

- - أثبت الكلمات الإملائية بالرسم الإملائي المعاصر، ولم أشر إلى ذلك في الهامش اكتفاء بها ذكرته هنا).

$$
\text { - ثانيًا : الجبت الآيات القرآب آنية برسم المصحسية: }
$$

- - خرجت الأحاديث والآثار من مضانها، وإن كان الحديث في البخاري ومسلم اكتفيت به، وإن لم يكن

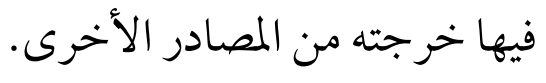


- ترجمت للأعلام الذين ذكرهم المصنف عند ورود العلم لأول مرة إلا المشهورين، فلم أترجم هم

$$
\text { كالخلفاء الر اشدين والأئمة الأربعة. }
$$

- عرفت أغلب الأماكن والبلدان التي وردت في المخطوط إلا الأماكن المعروفة، فلم أترجم ها. - مضعت فهارس علمية للكتاب لمزيد من الفائدة مثل فهارس للآيات القرآنية، والأعلام، والبلدان،

$$
\text { - ألأقواس التي استعملتها في التحقيق: المصادر والمراجع. }
$$

ب- - القوسان المعقوفان [ ] لما يضاف الى الأصل من النسخ الأخرى مع الإشارة المى ذلك في الهامش.

\section{المبحث الثالث: وصف النسخ الخطيَّة، ونهاذج من نسخ المخطوط: المطلب الأول : وصف النسخ الخطية:}

خطوط رسالة القهوة من المخطوطات الغنية بالمادة العلمية وقد حصلت على ثلاث نسخ للمخطوط.

النسخة الأولى: من مكتبة وزارة الاوقاف المصرية واعتمدها لتكون الأصل ورمزت لها ب(أ). - - وسبب اختيارها؛ لأنها الاقدم تاريخا، والأوضح خطاً. - - اسم المؤلف: : محمد بن محمد بن مصطفى الخادمي. - - اسم الناسخ: غير معروف - تاريخ النسخ : (1157) . - عدد اللوحات: (1) ع (1) - عدد الأسطر : (19 ) سطر. - عدد الكلمات: (20) في كل سطر تقريباً . 
- نوع الخط: خط التعليق -

- رقم المخطوط: (1238) - رق.

النسخة الثانية: من مكتبة دار الكتب القطرية ورمزت لها (ب).

- التصنيف: فقه حنفي .

- اسم المؤلف: : محمد بن محمد بن مصطفى الخادمي.

- - اسم الناسخ: غير معروف

- تاريخ النسخ :غير موجود.

- عدد اللوحات: (1).

- - عدد الأسطر : (20) سطر.

- - عدد الكلمات: (18) في كل سطر تقريباً.

- نوع الخط: خط التعليق .

- رقم المخطوط: (121) .

النسخة الثالثة: من المكتبة القادرية ورمز لها(ج).

- التصنيف: فقه حنفي ·

- اسم المؤلف: محمد بن محمد بن مصطفى الخادمي.

$$
\text { - اسم الناسخ: غير معروف }
$$

- تاريخ النسخ :غير موجود.

- عدد اللوحات: (1) ع (1)

- - عدد الأسطر : (16 ) سطر.

- عدد الكلمات: (15 -7 17) في كل سطر تقريباً.

- نوع الخط: خط التعليق . 
Website : www.uoajournal.com

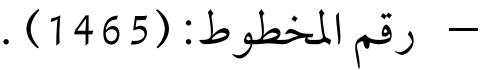

\section{المطلب الثاني: نهاذج من نسخ المخطوط:}

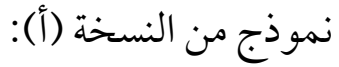

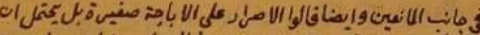

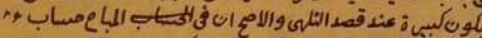

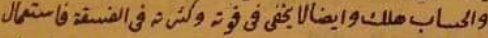

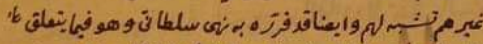

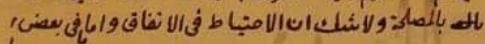

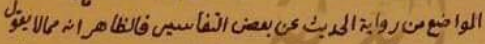

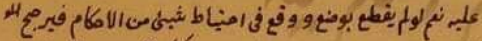

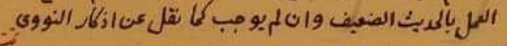

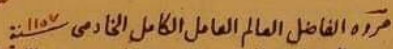

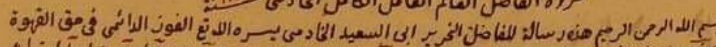

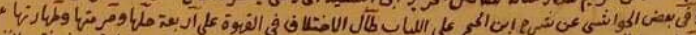

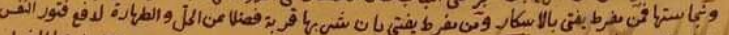

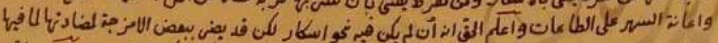

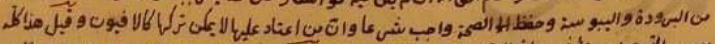

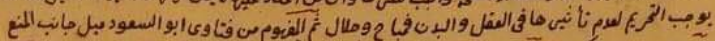

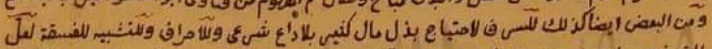

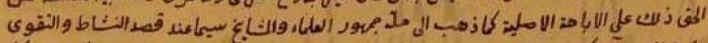

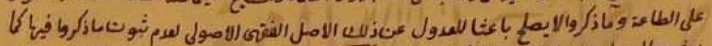

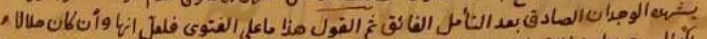

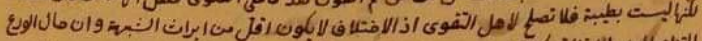

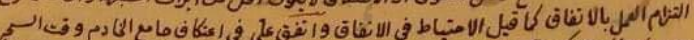

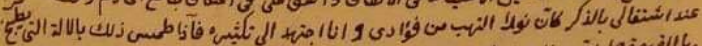

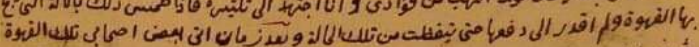

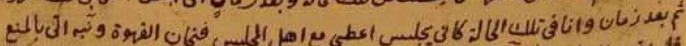

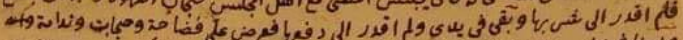

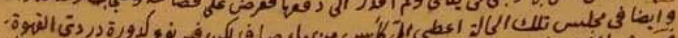

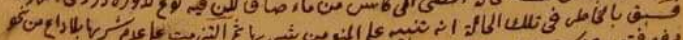

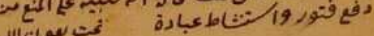

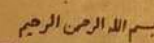

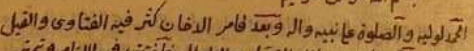

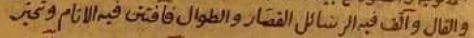

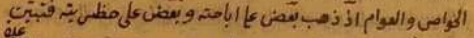

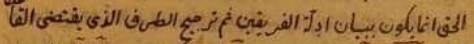

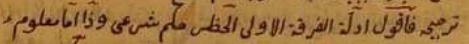

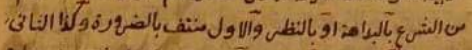

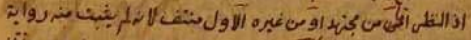

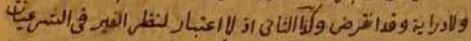

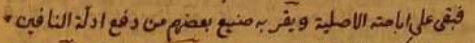

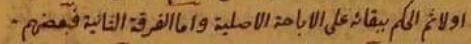

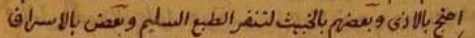

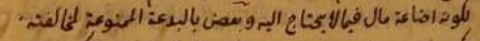

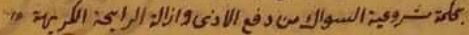

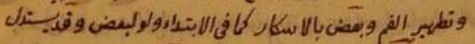

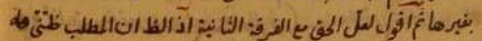

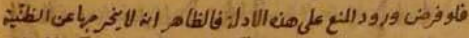

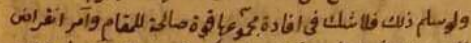

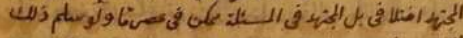

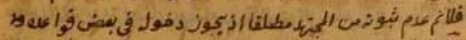
Hall

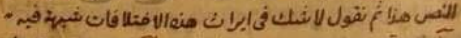

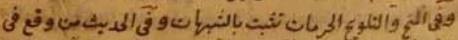

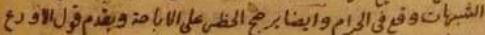

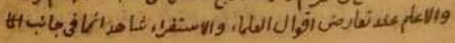

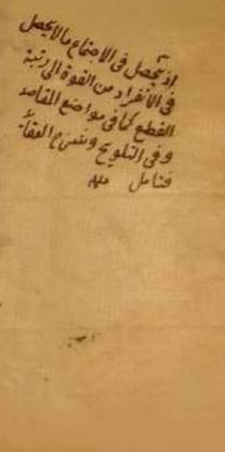




$$
\text { نموذج من النسخة (ب): }
$$

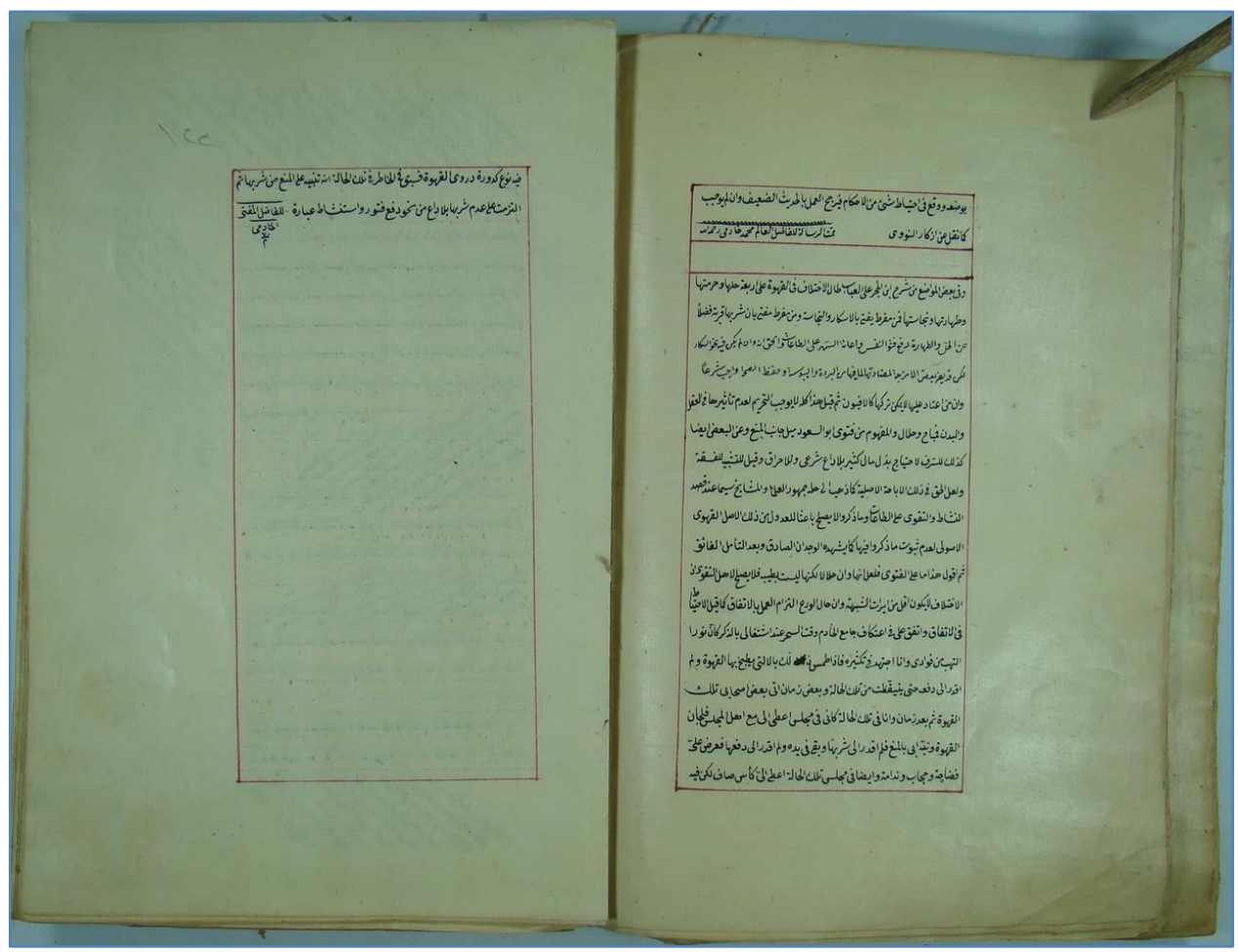

نموذج من النسخة (ج)

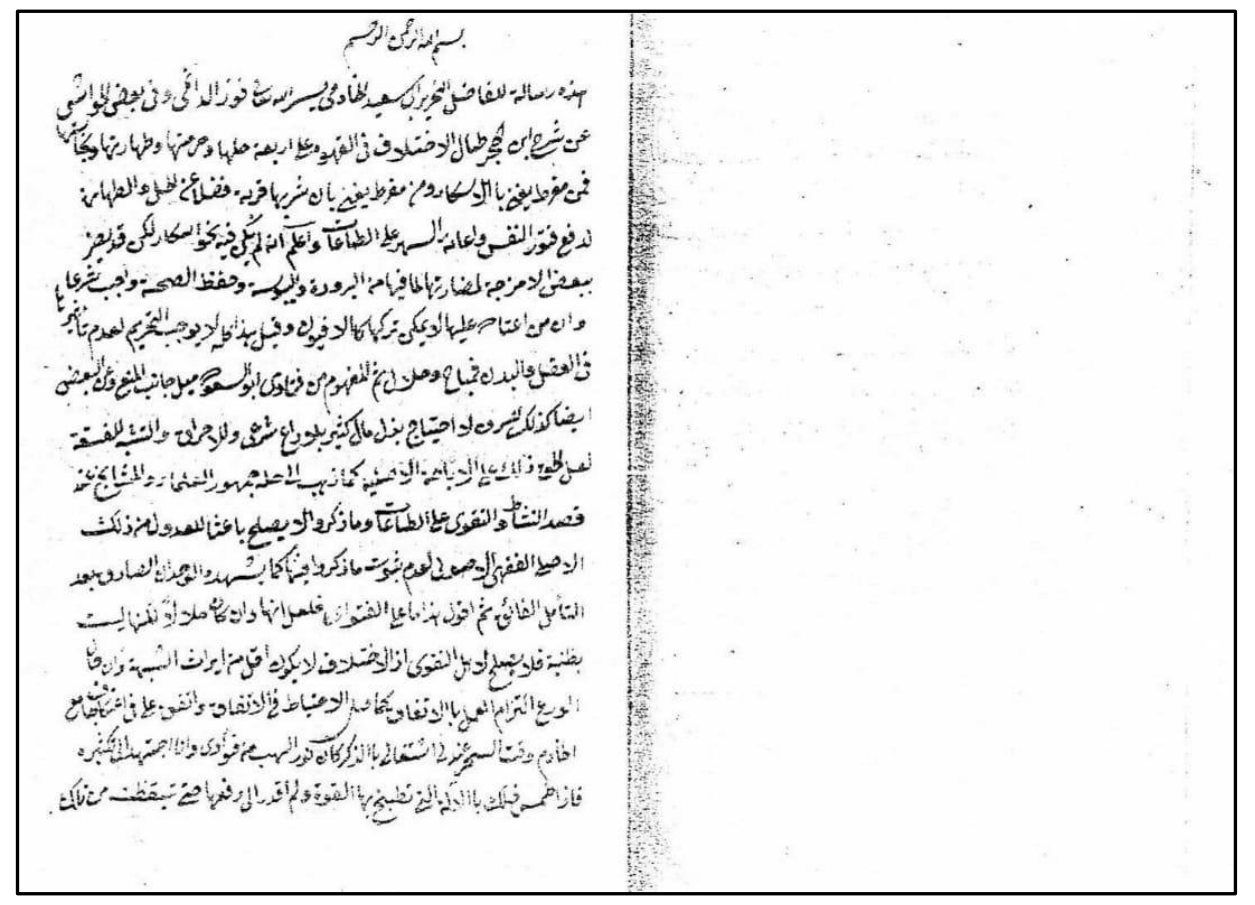


النص المحقق:

بسم الله الرحمن الرحيم

هذه رسالة للفاضل النحرير (29) أبي [سعيد](30) الخادمي، يسره الله تعالى الفوز (31) الدائمي في حق القهوة(32)، وفي بعض الحو اشي (33) عن(34) شرح ابن الحجر (35) على [العباب][36) (37)، طال الاختلاف في القهوة على أربعة، حلها، وحرمتها، وطهارتها، ونجاستها(38)، فمن مفرط يفتي بالإسكار [و النجاسة] (39)، ومن مفرط يفتي بأن شربها قربة، فضلا عن الحلّ والطهارة، [لدفع](40) فتور النفس واعانة السهر على الطاعات(41)، واعلم (42) الحقت (43) أنه ان لم يكن فيه نحو اسكار، لكن قد يضر ببعض الأمزجة لمضادتها، لما فيها من البرودة، و اليبوسة، وحفظ الصحة واجب شرعا، وإن من اعتاد عليها لا يمكن تركها، كالأفيون(44)، و (45)قيل هذا كله لا يوجب التحريم (46)؛ لعدم تأثيرها في العقل والبدن، فمباح وحلال، ثم (47) المفهوم من فتاوى(48) أبو (49) السعود(50) ميل جانب المنع (51)، وعن][52) البعض أيضا كذلك للسرف، لاحتياج بذل مال كثير بلا داع شرعي، وللإحراق و[قيل] (53) للتشبيه(54) للفسقة، لعل الحق [في](55) ذلك على (56) الإباحة الأصلية، كما ذهب الى ملة جمهور العلم)ء والمشايخ، سيم|(57) عند قصد النشاط، والتقوي على الطاعة(58)، وما ذكروا لا يصلح باعثا للعدول عن ذلك، الأصل الفقهي (59) الأصولي(60)؛ لعدم ثبوت ما ذكروا فيها، كما يشهد الوجدان الصادق بعد التأمل الفائق، ثم القول هذا ما على الفتوى(61)، فلعل أنها وان كان(62) حلالا، لكنها ليست بطيبة(63)، فلا تصلح لأهل التقوى، إذ الاختلاف لا يكون أقل من إيراث الشبهة(64)، وإن حال الورع التزام العمل بالاتفاق، كما قيل الاحتياط في الإنفاق، وانفق علي في اعتكاف جامع الخادم وقت السحر، عند اشتغالي بالذكر، كأن نورا التهب من فؤادي وأنا اجتهد إلى (65) تكثيره، فاذا طمس ذلك بالآلة(66) التي (67) يطبخ بها القهوة، ولم أقدر إلى دفعها حتى تيقظت من تلك الحالة، وبعد(68) زمان أتى بعض أصحابي تلك القهوة، ثم بعد زمان وأنا في تلك الحالة، كأني [في مجلس](69) أعطى [إلي](70) مع أهل المجلس فنجان القهوة، ونبه إليّ بالمنع فلم أقدر إلى شربها، وبقى في يدي(71) ولم أقدر إلى دفعها، فعرض علي فضاحة، وحجاب، وندامة، وأيضا في بجلس تلك الحالة، أعطى إلي كأس من (72) ماء(73) صاف(74). 
لكن فيه (75) نوع (76) كدورة دروى (77) القهوة، فسبق بالخاطر (78) في تلك الحالة، أنه تنبيه على المنع من شربها، ثم التزمت على عدم شربها بلا داع من نحو دفع فتور، واستنشاط عبادة، تمت بعون الله (79).

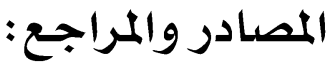

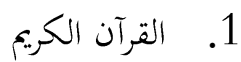

2. الأعلام للزركلي: لخير الدين بن محمود بن محمد بن علي بن فارس، الزركلي الدمشقي (ت: 1396ه)، دار العلم للملايين - ط-

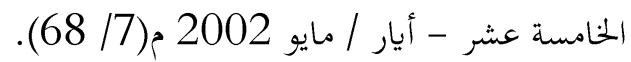

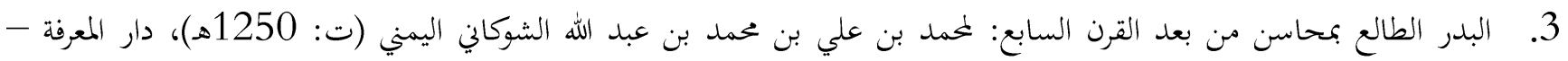

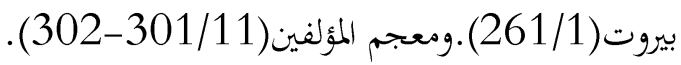

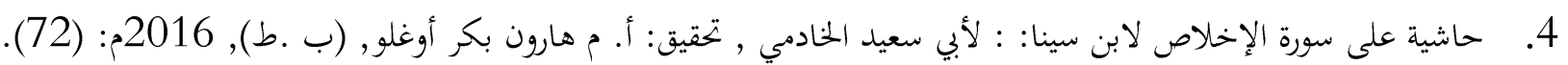

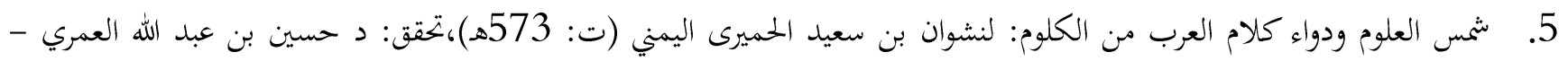

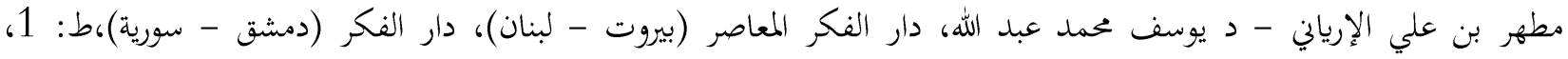

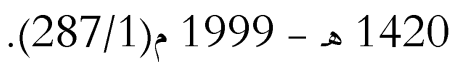

6. فتاوى الرملي: لشهاب الدين أحمد بن حمزة الأنصاري الرملي الشافعي (ت: 957هـ)،معها: ابنه، شمس الدين محمد بن أبي العباس

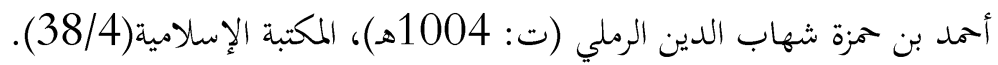

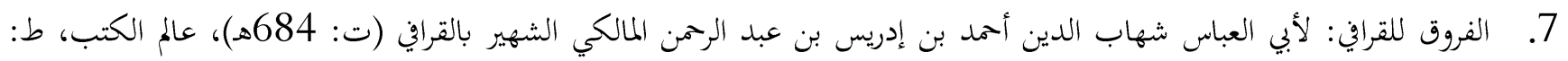

$$
\text { (221/1) (2/2/2) }
$$

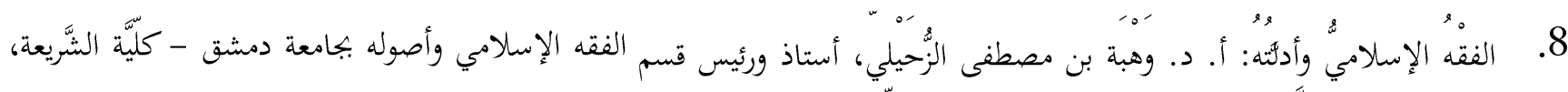

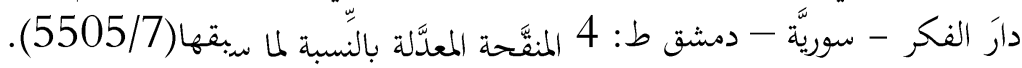

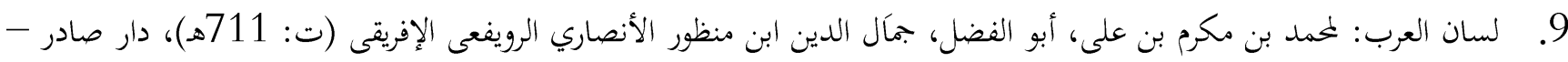

$$
\text { بيروت، ط: } 3 \text { - } 1414 \text { هـ. (197/5). }
$$

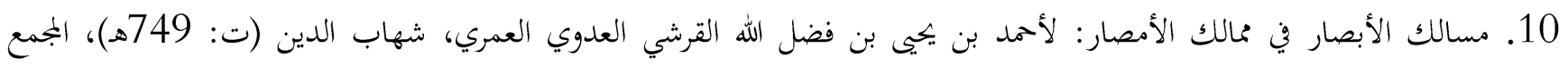

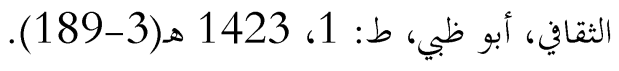

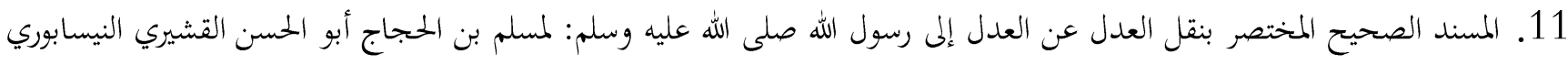

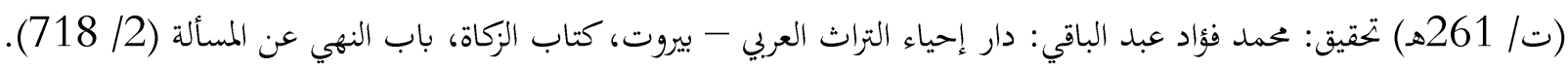

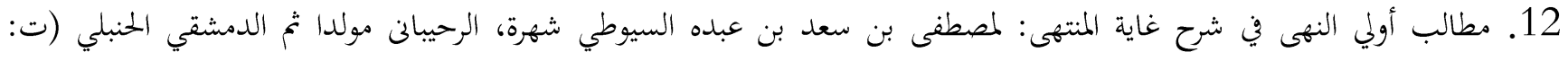

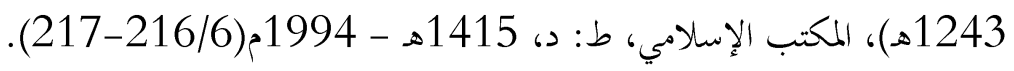


13. معجم البلدان: لشهاب الدين أبو عبد الله ياقوت بن عبد الله الرومي المموي (ت: 626ه)، دار صادر، بيروت- ط- الثانية،

. 1953 /1) 1995

14. معجم المفسرين لامن صدر الإسلام وحتى العصر الحاضر|": لعادل نويهض، قدم له: مفتي الجمهورية اللبنانية الشَّيخ حسن خالد،

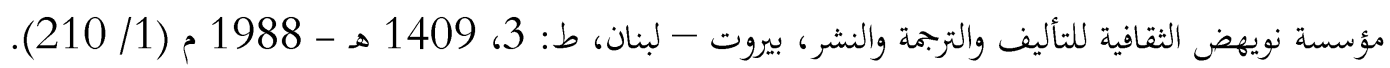

15. معجم المؤلفين: لعمر بن رضا بن محمد راغب بن عبد الغني كحالة الدمشق (ت: 1408هـ)، مكتبة المثنى - بيروت، دار إحياء التراث

$$
\text { العربي بيروت (11/ 301). }
$$

16. مناهج المفسرين: لمنيع بن عبد الحليم محمود (ت: 1430هـ)، دار الكتاب المصرى - القاهرة، دار الكتاب اللبنان - بيروت،

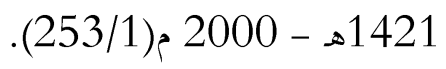

17. نثل النبال بمعجم الرجال الذين ترجم لهم فضيلة الشيخ المحدث أبو إسحاق الحويني، جمع من كتب: الشيخ أبي إسحاق الحويني، جمعه

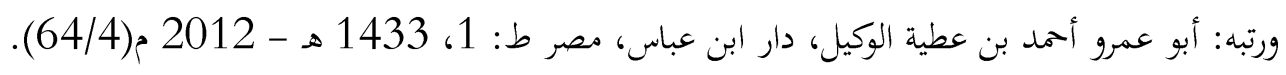

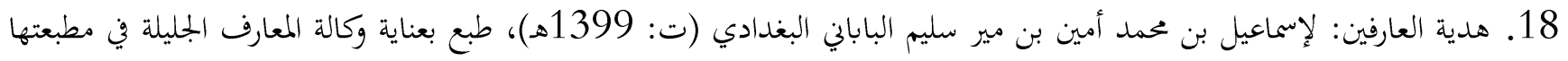

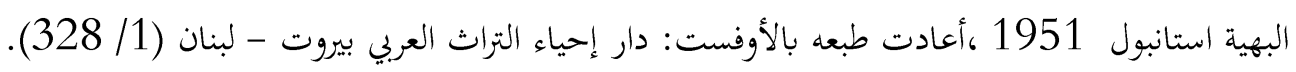

\section{الهوامش:}

(1) المسند الصحيح المختصر بنقل العدل عن العدل إلى رسول الله صلى الله عليه وسلم: لمسلم بن الحجاج أبو الحسن القشيري النيسابوري

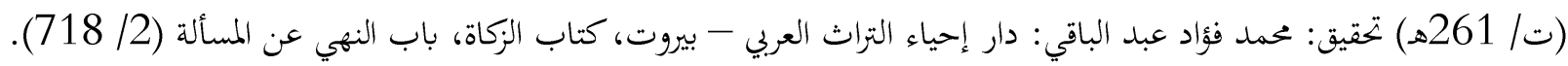

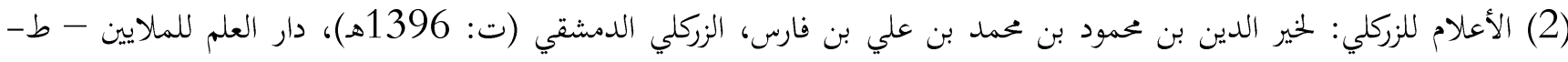

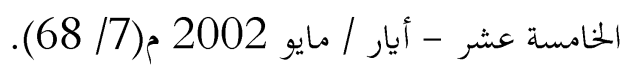

(3 ) بخارى: بالضم: من أعظم مدن ما وراء غر جيحون وأجلَها، وبينها وبين النهر يومان، وكانت قاعدة ملك السامانية، معجم البلدان:

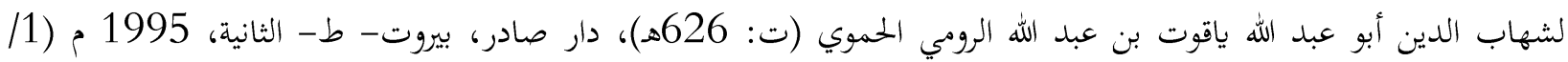

. (353

(4) قرية خادم: وهي قرية من توابع قنوية, وقنوية: هي مدينة جميلة من أعظم مدن الإسلام في بلاد الروم بها وبأقصرى سكنى ملوكها، وهي

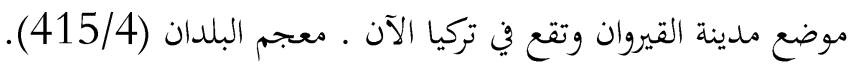

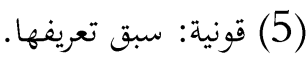

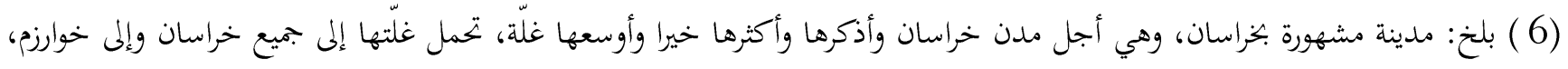

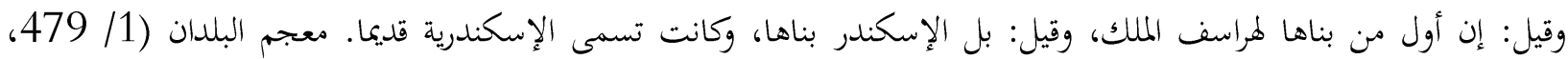


(8) الأعلام للزركلي (7/ 68), ومعجم المؤلفين: لعمر بن رضا بن محمد راغب بن عبد الغني كحالة الدمشق (ت: 1408ه)، مكتبة المثنى

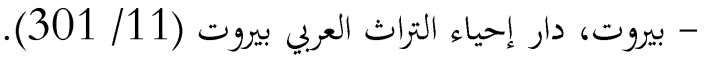

$$
\begin{aligned}
& \text { (9) معجم المؤلفين (12/ 31). }
\end{aligned}
$$

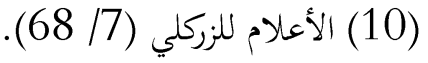

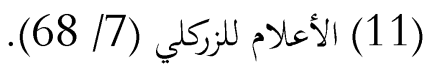

(12) معجم المفسرين (امن صدر الإسلام وحتى العصر الحاضره: لعادل نويهض قدم له: مفتي الجمهورية اللبنانية الشَّيخ حسن خالد،

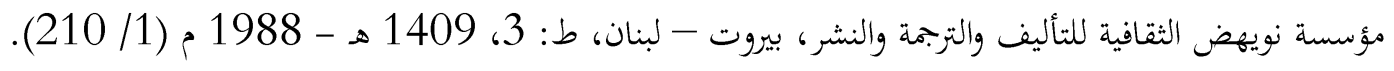

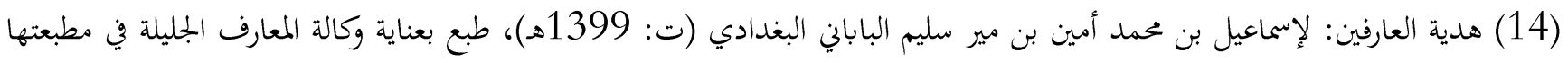

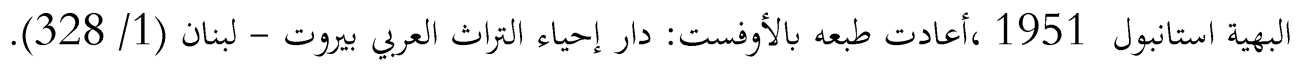

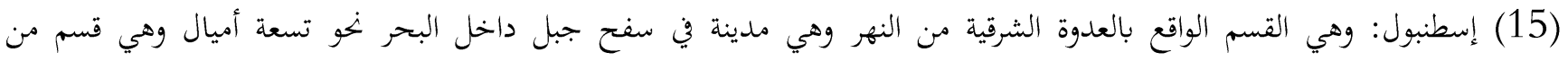

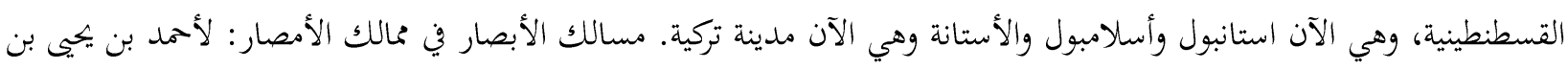

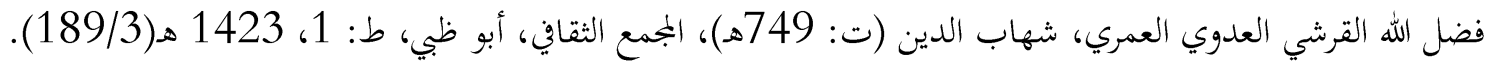
(16) مانم اجد له ترجمة في المصادر. (17) حاشية على سورة الإخلاص لابن سينا: : لأبي سعيد الخادمي , تحقيق: أ. م هارون بكر أوغلو, (ب .ط), 2016م.

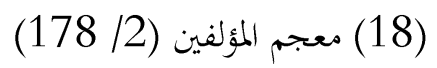

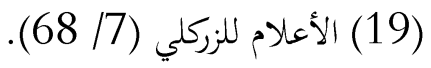

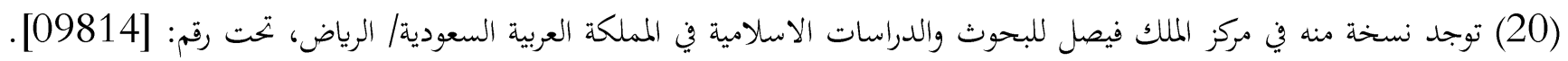

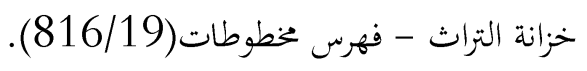

(21) توجد نسخة منه في دار الكتب القطرية/ قطر/الدوحة/ قسم العقيده وعلم الككام تحت رقم: [538]، و مكتبة المخطوطات/

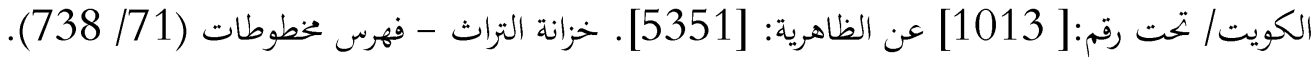

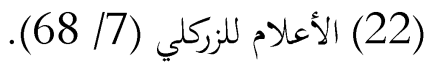

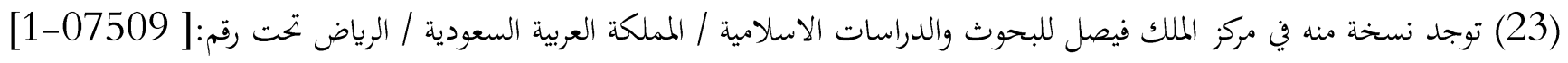
خزانة التراث - فهرس خغطوطات (111/ 712). (25) (25) الأعلام للزركلي (17/ 68 (238).

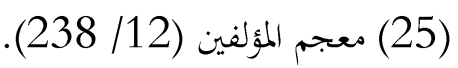

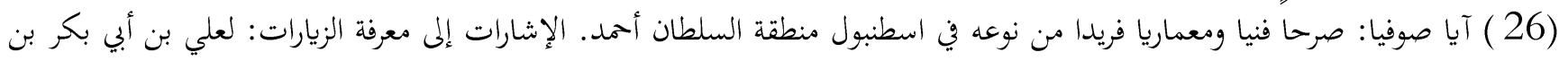

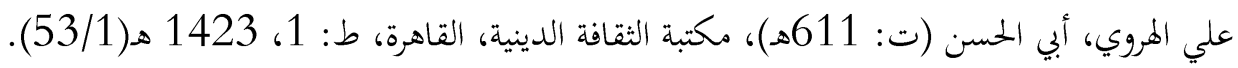

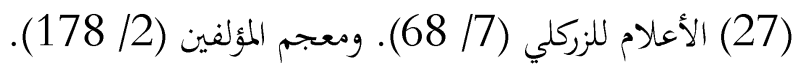




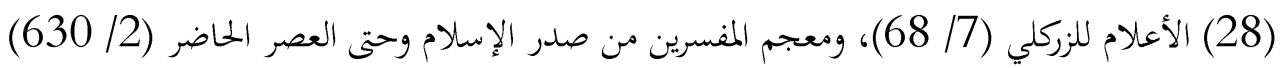

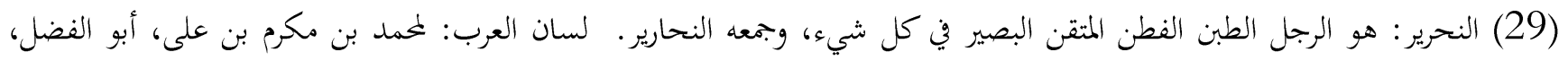

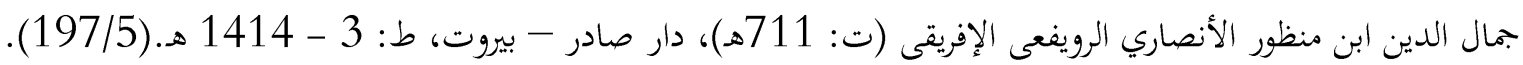

$$
\begin{aligned}
& \text { (30) في (أ): "السعيد" وما أثتته من (ج). }
\end{aligned}
$$

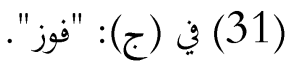

(32) عبارة: "هذه رسالة للفاضل النحرير ابي السعيد الخادمي يسره الله تعالى الفوز الدائمي في حق القهوة " سق من (ب)، وعبارة: " في

$$
\begin{aligned}
& \text { حق القهوة " سقط من(ج). } \\
& \text { (33) في (ب): "لمواضع". } \\
& \text { (34) في (ب): "من". }
\end{aligned}
$$

(35) ابن حجر الهيتمي: هو أبو العباس، أمد بن محمد بن محمد بن علي شهاب الدين المكي الشافعي الفقيه، 899 - 974 هـ هـ تتلمذ

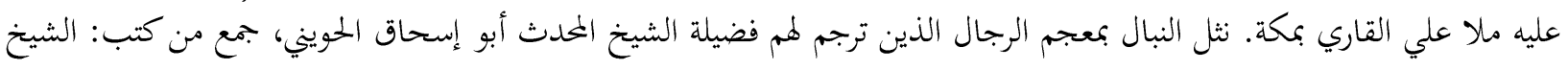

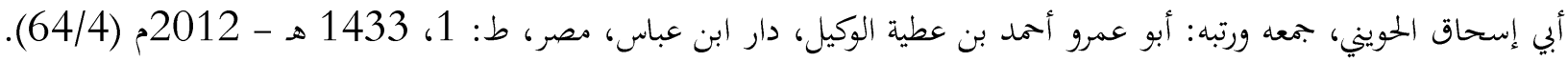

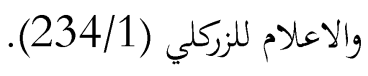$$
\text { (36) في (أ): "اللباب" وما أثتبه من (ب) (234)، وعبارة: "على العباب" لم تذكر في (ج). }
$$

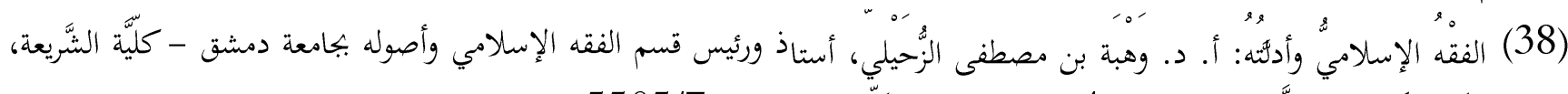

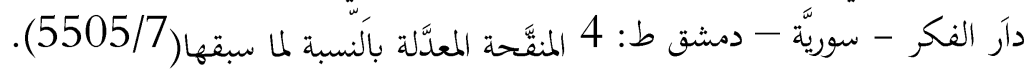

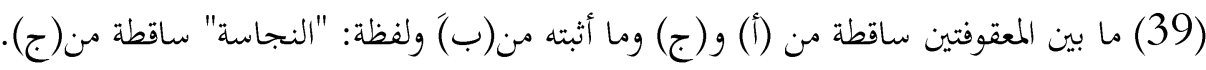

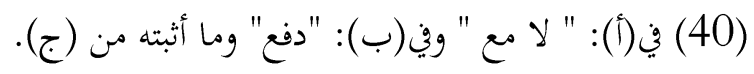

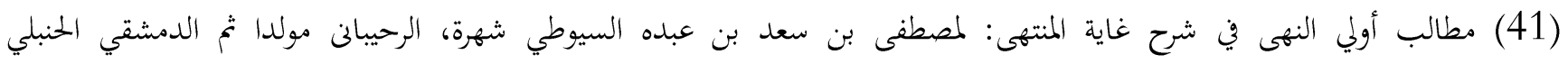

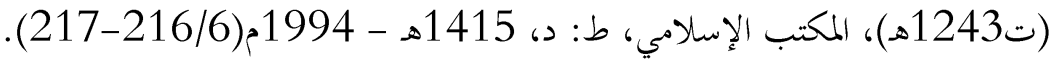

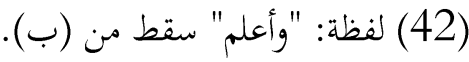

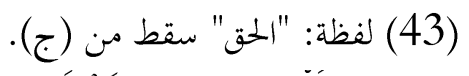

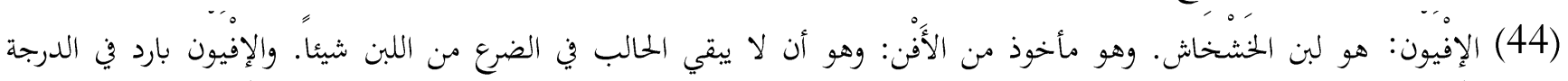

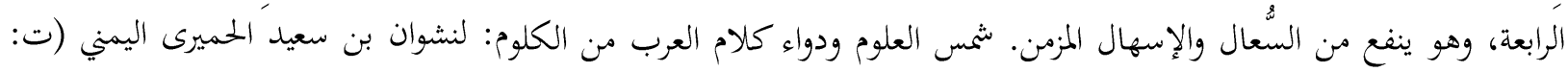

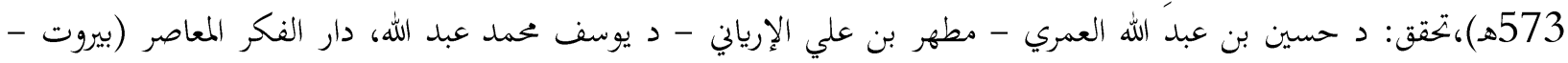

$$
\begin{aligned}
& \text { لبنان)، دار الفكر (دمشق - سورية)،ط: 1، } 1420 \text { هـ - } 1999 \text { م م(287/1). }
\end{aligned}
$$

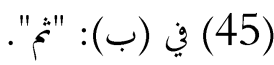


(46) فتاوى الرملي: لشهاب الدين أحمد بن حمزة الأنصاري الرملي الشافعي (ت: 957هـ)،همعها: ابنه، شمس الدين محمد بن أبي العباس

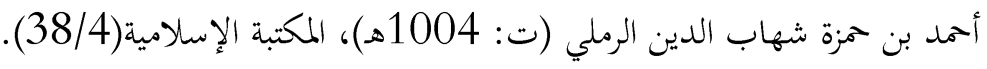

$$
\begin{aligned}
& \text { (47) في (ب): "والمفهوم". } \\
& \text { (48) في (ب): "قتوى". }
\end{aligned}
$$

(49) في جميع النسخ: "أبو "والصواب: "أبي " لأنه مضاف إليه ولكونه من الأسماء الخمسة ومعلوم أن الأسماء الحمسة بتحر بالياء ولعله سهو

$$
\text { من النساخ. }
$$

(50) هو محمد بن محمد بن مصطفى العبادي الحنفي ،ابو السعود ،فقيه اصولي مفسر من موالي الروم له تصانيف منها ،ارشاد العقل السليم

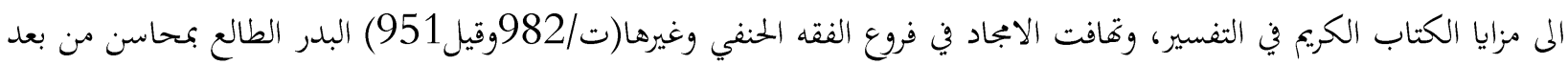

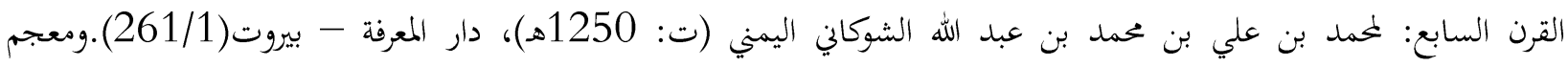

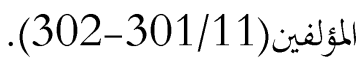

(51) مناهج المفسرين: لمنيع بن عبد الحليم محمود (ت: 1430هـ)، دار الكتاب المصري - القاهرة، دار الكتاب اللبناني - بيروت،

$$
\begin{aligned}
& \text { 1421هـ - 253/1) } 2000 \text { م) }
\end{aligned}
$$

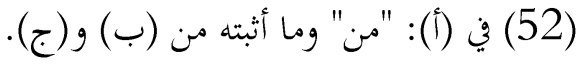

$$
\begin{aligned}
& \text { (53) الزيادة من (ب). (1) }
\end{aligned}
$$

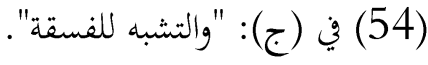

$$
\begin{aligned}
& \text { (55) الزيادة من (ب). (5) (ول) }
\end{aligned}
$$

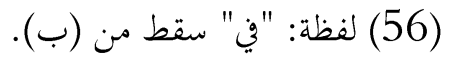

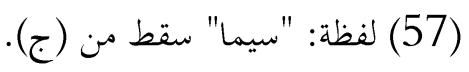

$$
\begin{aligned}
& \text { (58) في (ب) و(ج): "الطاعات". } \\
& \text { (59) في (ب): "القهوي". (ب) : الطاعال }
\end{aligned}
$$

(60) الفروق للقرافي: لأبي العباس شهاب الدين أحمد بن إدريس بن عبد الرممن المالكي الشهير بالقرافي (ت: 684هـ)، عالم الكتب، ط:

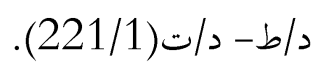

(61) رد المختار على الدر المختار: ابن عابدين، محمد أمين بن عمر بن عبد العزيز عابدين الدمشقي الحنفي (ت: 1252هـه)، دار الفكر -

$$
\begin{aligned}
& \text { بيروت، ط: 2، 1412هـ - 1992م(4) (461/6). } \\
& \text { (62) لفظة: "كان" ساقط من (ب). } \\
& \text { (63) فئ (ج): "بظنية". }
\end{aligned}
$$

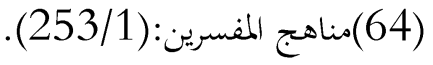

$$
\begin{aligned}
& \text { (65) في (ب): "في". } \\
& \text { (66) لفظة: "الآلة" سقط من (ب). }
\end{aligned}
$$




$$
\begin{aligned}
& \text { (67) في (ب): "بالتي". }
\end{aligned}
$$

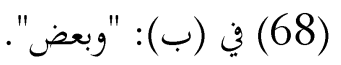

$$
\begin{aligned}
& \text { (69) الزيادة من (ب) وئ (أ): "يجلس". } \\
& \text { (70) الزيادة من (ب) و(ج). } \\
& \text { (71) في (ب): "يده". } \\
& \text { (72) لفظة: "من" سقط من (ج). }
\end{aligned}
$$

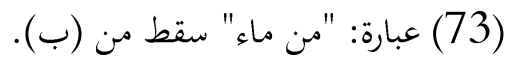

$$
\begin{aligned}
& \text { (74) في (ج): "صفاء". } \\
& \text { (75) لفظة: "فيه" مكررة في (ب). } \\
& \text { (76) في (ج): "لكن نوع فيه" وهو تقديم و تأخير. } \\
& \text { (77) في(ج): "ذروى". } \\
& \text { (78) في (ب): "في الخاطر". } \\
& \text { (79) جملة " تمت بعون الله " لم تذكر في (ب) وجاء في فايتها : "للفاضل المفتي الحنادمي"، وجاء في (ج): "تمت بعونه ولطفه وكرمه". }
\end{aligned}
$$

